Article

\title{
$\alpha$ - and $\beta$-Diversity Patterns of Macrophytes and Freshwater Fishes are Driven by Different Factors and Processes in Lakes of the Unexplored Southern Balkan Biodiversity Hotspot
}

\author{
Anthi Oikonomou *(D) and Konstantinos Stefanidis $(D$ \\ Hellenic Centre for Marine Research, Institute of Marine Biological Resources and Inland Waters (IMBRIW), \\ 46.7 km of Athens-Sounio Ave., P.O. Box 712, 19013 Anavissos Attica, Greece; kstefanidis@hcmr.gr \\ * Correspondence: anthi.oikon@gmail.com
}

Received: 11 June 2020; Accepted: 9 July 2020; Published: 13 July 2020

\begin{abstract}
Disentangling the main drivers of species richness and community composition is a central theme in ecology. Freshwater biodiversity patterns have been poorly explored; yet, it has been shown that different freshwater biota have different, often contrasting responses to environmental gradients. In this study, we investigated the relative contribution of geographical and environmental (habitat-, climate- and water quality-related) factors/gradients in shaping the $\alpha$-and $\beta$-diversity patterns of macrophytes and fish in sixteen natural freshwater lakes of an unexplored Balkan biodiversity hotspot, the Southern Balkan Peninsula. We employed generalized linear modeling to identify drivers of $\alpha$-diversity, and generalized dissimilarity modeling to explore commonalities and dissimilarities of among-biota $\beta$-diversity. Species richness of both biota was significantly associated with lake surface area, whereas macrophytes had an inverse response to altitude, compared to fish. Both species turnover and nestedness significantly contributed to the total $\beta$-diversity of macrophytes. In contrast, species turnover was the most significant contributor to the total fish $\beta$-diversity. We found that the compositional variation of macrophytes is primarily limited by dispersal and ultimately shaped by environmental drivers, resulting in spatially structured assemblages. Fish communities were primarily shaped by altitude, highlighting the role of species sorting. We conclude that among-biota diversity patterns are shaped by different/contrasting factors, and, thus, effective/sustainable conservation strategies should encompass multiple aquatic biota.
\end{abstract}

Keywords: compositional dissimilarity; discordance; lentic; generalized dissimilarity modeling; spatial patterns; species richness; Balkan freshwaters

\section{Introduction}

After pioneer works by C. Darwin (1839), A.R. Wallace (1878), and R.H. MacArthur (1972) [1-3], unveiling the factors and the underlying processes that spatially shape biodiversity is one of the most fundamental themes in ecology and biogeography [4]. In recent years, ecological research has shifted focus from exploring local (termed $\alpha$-diversity) or regional species richness patterns (termed $\gamma$-diversity) to understanding how species composition varies spatially (termed $\beta$-diversity) and which factors may generate such variation [5-10].

For $\alpha$ - diversity, various historical, environmental, and geographical factors [11] have long been recognized as major drivers, with their relative importance being the key approach to understanding the mechanisms and rules of community assembly $[12,13]$. For $\beta$-diversity, studies have shown that environmental filtering is the strongest mechanism, responsible for high compositional dissimilarities, as species sort themselves along environmental gradients [14-18]. Moreover, community dissimilarity 
increases as the geographical distance between two communities increases (distance decay) [19], since neighboring communities are more structurally similar than those located further apart [14]. This pattern also highlights the importance of dispersal limitations, further suggesting inherent neutrality and stochasticity [20]. As total $\beta$-diversity is partitioned into two additive components, accounting for pure spatial turnover and nestedness, many hypotheses have been proposed to describe the underlying ecological processes [21], since these two components imply different mechanisms structuring species assemblages. Spatial turnover refers to the replacement of some species by others as a consequence of environmental filtering and/or spatial and historical constraints [18,22-24]. Conversely, nestedness reflects the spatial pattern, in which assemblages in depauperate ecosystems are subsets of communities of successively richer ecosystems [25] and stems from species loss caused by different processes, such as selective colonization and extinction [26]. Diversity-based research has long focused on terrestrial vertebrates and vascular plants, with studies on freshwater ecosystems being limited [27]. Few attempts have been made to investigate the effects of both space and environment on taxonomic richness and composition variation of diverse freshwater biota with varying dispersal traits [28-33], despite the fact that lacustrine habitats are analogous to terrestrial ones, often conceptualized as habitat islands [34].

The Balkan Peninsula has long been recognized as a European freshwater biodiversity hotspot [35] with extraordinary high compositional dissimilarity of its aquatic biota [36]. It is characterized by recent geological formations with distinctive geographical barriers, highly fragmented hydrographic networks [37], and the existence of many lakes, remnants of the Tethys and Paratethys seas [38].

In this study, we investigated the relative contribution/importance of environmental (habitat-, climate- and water quality-related) and geographical factors/gradients on shaping the $\alpha$ - and $\beta$-diversity patterns of two highly diverse, differing in dispersal mechanisms freshwater biota, aquatic macrophytes and fish, across sixteen natural lakes of the Southern Balkan Peninsula. Our primary hypothesis was that macrophytes and fish show similar patterns of species richness along the same environmental/geographical gradients. We further assessed total $\beta$-diversity of each biota, partitioned into species turnover and nestedness, assuming that good dispersers, such as macrophytes, will have less biogeographical variation than actively dispersing organisms (bad dispersers), such as fish. Finally, we developed Generalized Dissimilarity Models (GDMs) to evaluate the relative contribution of environmental and geographical factors in explaining variation in the three $\beta$-diversity components (total, species turnover, and nestedness), hypothesizing that passively dispersing organisms with good dispersal ability would be subject to stronger environmental control/filtering than actively dispersing organisms (bad dispersers) across the Southern Balkan lakes.

\section{Materials and Methods}

\subsection{Study Area and Data Collection}

Sixteen natural lakes of the southern Balkans were studied, eleven exclusively located in Greece, one in Bulgaria, and four transboundary lakes, shared between two or more countries (Figure 1). All lakes belong to five groups of drainage basins corresponding to five distinct, major biogeographical regions of the Balkan Peninsula, although with short geographical distance between them (see [30]). The eleven exclusively Greek lakes are included in the Natura 2000 network (except for the Ziros Lake) as sites of Community importance (SCIs), Special Conservation Areas (SCAs), and Special Protected Areas (SPAs). The transboundary Prespa lakes have been defined as a Greek National Park and a wetland of international importance under the Ramsar Convention. Lake Skadar is also a Ramsar site since 1996 and a national park in Montenegro since 1983. Lakes Ohrid between Albania and North Macedonia and Srebarna in Bulgaria are both listed as World Heritage Sites. All lakes were selected based on data availability and geographical representation (see Figure 1). 


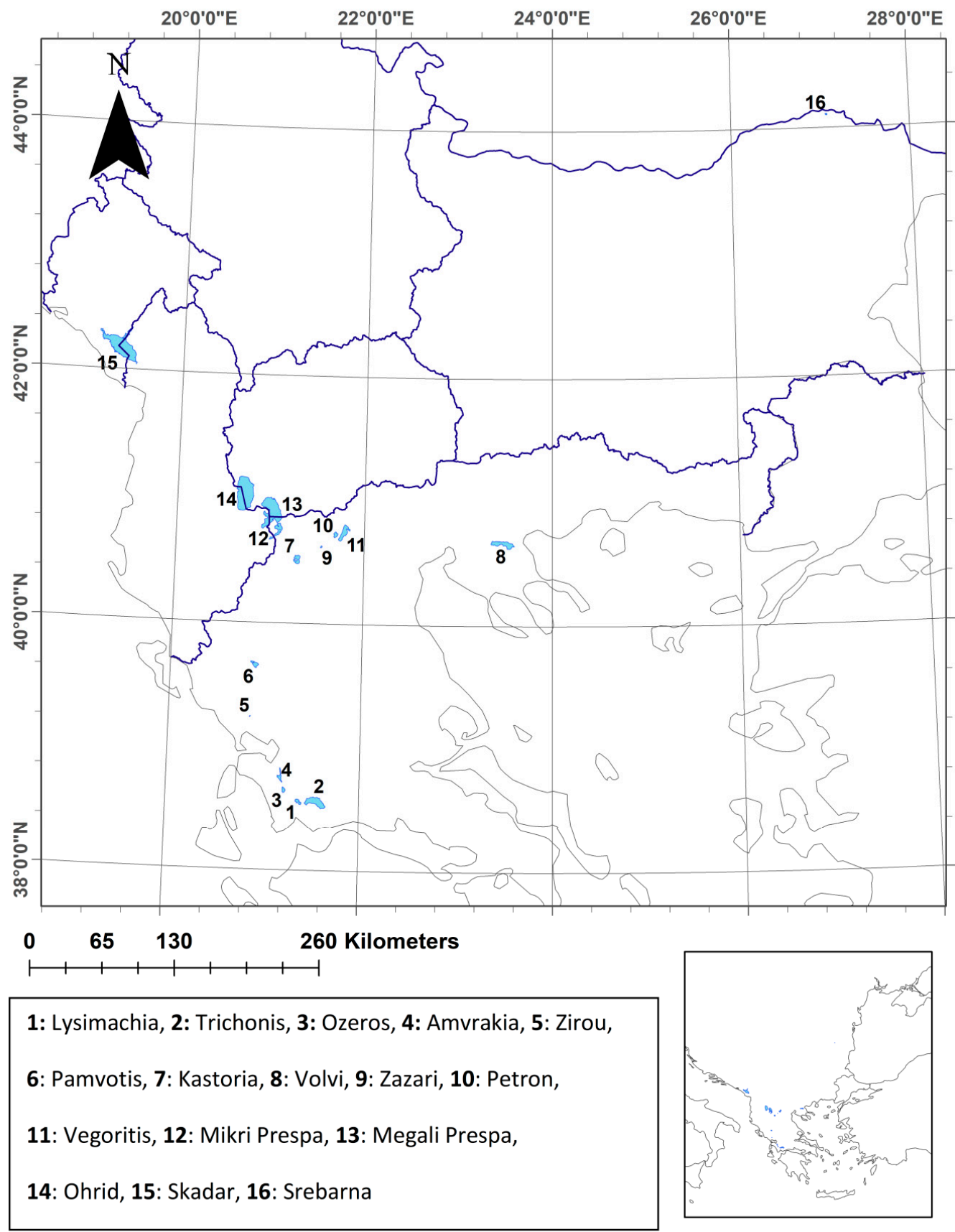

Figure 1. Location of the sixteen studied lakes in the Southern Balkan Peninsula.

Thirteen environmental variables were categorized into three groups in accordance with [39]: (1) climate $(\mathrm{n}=6)$; (2) water quality $(\mathrm{n}=2)$; and (3) habitat heterogeneity $(\mathrm{n}=5)$ (Table 1$)$. All habitat heterogeneity values, except for maximum depth, were calculated using the lakemorpho package in $R$ version 3.5.2 [40] using as input the lake polygon shapefiles obtained by the CORINE land cover 2012 inventory (https://land.copernicus.eu/pan-european/corine-land-cover/clc-2012/view). Monthly air temperatures and annual rainfall and precipitation for the year 2017 were acquired from the MERRA-2 database [41]. The elevation of each lake was obtained by accessing Google Earth imagery. The remaining variables, maximum depth, electrical conductivity, and $\mathrm{pH}$, were obtained from previous literature (Table S1, Supplementary material). 
Table 1. The thirteen environmental variables that were included in the analysis, categorized in three groups; habitat heterogeneity, climate and water quality.

\begin{tabular}{|c|c|c|}
\hline $\begin{array}{l}\text { Environmental } \\
\text { Descriptor }\end{array}$ & Variable & Description \\
\hline \multirow{5}{*}{$\begin{array}{c}\text { Habitat } \\
\text { heterogeneity }\end{array}$} & Lake surface & The area of the surface of the lake $\left(\mathrm{km}^{2}\right)$ \\
\hline & Fetch & $\begin{array}{l}\text { The longest unbroken stretch of open water on a } \\
\text { lake }(\mathrm{km})\end{array}$ \\
\hline & Shoreline length & $\begin{array}{l}\text { The lake perimeter/length of the shoreline of the } \\
\text { lake }(\mathrm{km})\end{array}$ \\
\hline & Shoreline development & $\begin{array}{c}\text { The ratio of the shoreline length to the length of } \\
\text { the circumference of a circle of area equal to that } \\
\text { of the lake }\end{array}$ \\
\hline & Maximum depth & The depth of the deepest point in the lake (m) \\
\hline \multirow{6}{*}{ Climate } & Average monthly air temperature & $\begin{array}{l}\text { Average monthly air temperature calculated by } \\
\text { monthly air temperatures for } 2017\left({ }^{\circ} \mathrm{C}\right)\end{array}$ \\
\hline & Maximum monthly air temperature & Maximum monthly air temperature of $2017\left({ }^{\circ} \mathrm{C}\right)$ \\
\hline & Minimum monthly air temperature & Minimum monthly air temperature of $2017\left({ }^{\circ} \mathrm{C}\right)$ \\
\hline & Rainfall & Annual rainfall $(\mathrm{mm})$ \\
\hline & Precipitation & Annual precipitation (rainfall and snowfall, $\mathrm{mm}$ ) \\
\hline & Altitude & Height of the lake location above sea level (m) \\
\hline \multirow[t]{2}{*}{ Water quality } & Conductivity & $\begin{array}{l}\text { Average electrical conductivity }(\mu \mathrm{S} / \mathrm{cm}) \text { based on } \\
\text { available measurements }\end{array}$ \\
\hline & $\mathrm{pH}$ & Average $\mathrm{pH}$ based on available measurements \\
\hline
\end{tabular}

\section{2. $\alpha$-Diversity}

Macrophyte and fish species richness and composition were assembled through an extensive literature review spanning form 1990 to the late 2010s, including research articles, dissertation theses, databases, and gray literature [36,42-49]. Helophytes were excluded and only macrophytes of the isoetids, elodeids, nymphaeids, lemnids, and charids growth forms were analyzed. Aquatic ferns and bryophytes were also considered in further analyses. Fish species richness and composition data were also assembled from existing literature (research articles, databases, and gray literature) [36]. Only native species were examined; species with uncertain natural presence were omitted from analysis. Overall, our database encompassed 62 macrophyte and 95 fish species.

\section{3. $\beta$-Diversity}

A plethora of metrics has been proposed for quantifying beta diversity (see review [5]); yet, there is still a debate among researchers on the use of beta diversity indices [50]. Following Baselga [21,26], the relative contribution of species turnover and nestedness to the total beta diversity was determined by partitioning beta diversity into two separate components of species turnover and nestedness-resultant dissimilarities using the Sørensen dissimilarity index accounting for total beta diversity $\left(\beta_{\text {Sør }}\right)$. $\beta_{\text {Sør }}$ was thus decomposed into $\beta_{\text {Sim }}$ (spatial turnover) and $\beta_{\text {Nes }}$ (nestedness); $\beta_{\text {Sør }}=\beta_{\text {Sim }}+\beta_{\text {Nes }}$.

Based on the presence/absence matrix with rows representing the different lakes and columns representing the macrophyte or fish species composition in each lake, we calculated $\beta_{\text {Sør }}$ as follows:

$$
\beta_{\text {sor }}=\frac{b+c}{2 a+b+c}
$$

where $\alpha$ is the number of species common between two lakes, $b$ is the number of species that occur in the first lake but not in the second, and $c$ is the number of species that occur in the second lake but not in the first. Spatial turnover was determined by calculating the Simpson dissimilarity index $\left(\beta_{\text {Sim }}\right)$ as follows:

$$
\beta_{\text {sim }}=\frac{\min (b, c)}{a+\min (b, c)}
$$

where $\alpha, b$, and $c$ denote the same variables as defined for $\beta_{\text {Sør. }}$. The nestedness-resultant component of Sørensen dissimilarity is simply the difference between $\beta_{\text {Sør }}$ and $\beta_{\text {Sim }}$, and it denotes the fraction of 
dissimilarity caused by richness differences between nested subsets [26]. The three $\beta$-diversity indices $\left(\beta_{\text {Sør }}, \beta_{\text {Sim }}\right.$, and $\left.\beta_{\mathrm{Nes}}\right)$ were calculated using package betapart in R [51].

\section{4. $\alpha$-Diversity Patterns-Generalized Linear Models (GLMs)}

To determine the environmental variables that best explained species richness patterns in the sixteen studied lakes, we implemented Generalized Linear Models (GLMs) with a Poisson error distribution and a logarithmic link function for macrophyte and fish species richness data. GLMs are a flexible extension of linear models, which allows for the incorporation of non-normal distributions of the response variable and nonlinear combinations of the explanatory variables. Prior to the analysis, to avoid multicollinearity and redundancy of variables, the number of variables included in the model was reduced by removing highly correlated variables $(r>0.7)$ through significance testing for each pair using the corrplot $\mathrm{R}$ package [52]. The variance inflation factor (VIF) was calculated using the car R package [53], and multicollinearity was assessed based on VIF; when VIF values $>10$ occurred, indicating high multicollinearity, only the variable with the lowest VIF was included in the analysis [54]. Based on the above, six variables, fetch, shoreline length, average monthly air temperature, maximum monthly air temperature, minimum monthly air temperature, and rainfall, were omitted from subsequent GLM analyses.

To determine the optimal model, we started with a global model containing all the explanatory variables included after the VIF assessment $(n=7)$. Then, we generated sub-model sets from the global model using the dredge function implemented in the MuMIn package [55]. We used the Akaike's information criterion corrected for small sample sizes (QAICc, [56]), to select explanatory variables driving total species richness, considering both goodness-of-fit and model complexity; the final model selected was the one with the lowest AICc value. GLMs were implemented with the MASS package [57]. AICc was calculated using the AICcmodavg v1.28 R package [58].

\section{5. $\beta$-Diversity Patterns_-Generalised Dissimilarity Modeling (GDM)}

Generalized Dissimilarity Models (GDMs) [59,60] were developed for modeling spatial variation in macrophyte and fish assemblages. GDMs are a reformulation of the Mantel approach into a GLM, and allow for predictive modeling of community dissimilarity against a set of environmental predictors while overcoming two major limitations; nonlinearities typical in ecogeographic datasets, and uneven rates of species turnover along environmental gradients [60]. GDMs were developed based on the compositional dissimilarity of native fish and macrophyte assemblages, quantified with the three indices of beta diversity $\left(\beta_{\mathrm{S} ø r}, \beta_{\text {Sim }}\right.$ and $\beta_{\mathrm{Nes}}$ ) between pairs of lakes in relation to lake-by-lake distance environmental matrices and geographical distance.

\section{Results}

\subsection{Predictors of $\alpha$-Diversity}

Macrophyte species richness ranged from 5 in the Zazari Lake to 31 in the Skadar Lake, the largest lake in the Balkans. The best GLM highlighted lake surface, $\mathrm{pH}$, and altitude as significant descriptors of macrophyte richness, with lake surface being the most influential variable, followed by $\mathrm{pH}$ and altitude (Table 2 and Figure S1). For fish richness, shoreline development was the most significant predictor of $\alpha$-diversity, showing a linear positive effect in fish species richness (Table 2). Lake area also had a positive significant effect whereas altitude had negative correlation with fish species richness variation (Figure S1). Regarding altitude, we found that fish species richness decreases substantially until the elevation of $400 \mathrm{~m}$, above which it shows small changes, whereas aquatic macrophyte richness increases with altitude showing highest rates of change between sea level and altitudes of about $200 \mathrm{~m}$. The response of both macrophyte and fish richness to lake area was unambiguous, with very similar patterns (Figure S1). 
Table 2. GLM results with macrophyte and fish richness ( $\alpha$-diversity) used as response variables.

\begin{tabular}{ccccc}
\hline Predictor & Estimate & Std. Error & Z Value & Sig. \\
\hline \multicolumn{5}{c}{ Macrophytes } \\
\hline (Intercept) & -74.638 & 29.411 & -20.538 & $*$ \\
Altitude & 0.2810 & 0.1036 & 2.714 & $* *$ \\
Surface & 0.4878 & 0.1267 & 3.851 & $* * *$ \\
pH & 97.756 & 32.260 & 3.030 & $* *$ \\
& \multicolumn{5}{c}{ Residual deviance: 14.041} \\
Shish \\
(Intercept) & 20.357 & 0.2482 & 8.202 & $* * *$ \\
Altitude & -0.5151 & 0.1133 & -4.548 & $* * *$ \\
Surface & 0.8385 & 0.1513 & 5.540 & $* * *$ \\
& 0.6423 & 0.1673 & 3.838 & $*$ \\
\hline \multicolumn{5}{c}{ Residual deviance: 7.6345} \\
\end{tabular}

\subsection{Components of $\beta$-Diversity}

Sørensen dissimilarity (i.e., total $\beta$-diversity) of macrophyte communities among lakes was relatively high (mean $\beta_{\text {Sør }}=60.1 \%$ ) (Table 3). Simpson dissimilarity (beta diversity due to species turnover) and nestedness dissimilarity (beta diversity due to nestedness-resultant richness differences) accounted for $37.13 \%$ and $22.96 \%$, respectively (Table 3). However, $\beta$-diversity of macrophytes was mainly explained by variation in species composition, rather than differences in species richness. In contrast, the total $\beta$-diversity for fish communities (i.e., Sørensen coefficient, $\beta_{\text {Sør }}$ ) was remarkably high $\left(\beta_{\mathrm{S} ø \mathrm{r}}=88.07 \%\right.$ ) and was attributed mainly to the species turnover component $\left(\beta_{\text {Sim }}\right)$, which accounted for $82.44 \%$ of the total $\beta$-diversity variation (Table 3 ).

Table 3. Total $\beta$-diversity (Sorensen, $\beta_{\text {Sør }}$ ), Simpson dissimilarity (species turnover, $\beta_{\text {Sim }}$ ), and nestedness dissimilarity $\left(\beta_{\mathrm{Nes}}\right)$ for macrophytes and fish in the studied lakes.

\begin{tabular}{cccccccc}
\hline Biota & Component & Min & 1st Qu & Median & Mean & 3rd Qu & Max \\
\hline \multirow{4}{*}{ Macrophytes } & $\beta_{\text {Sør }}$ & 0.152 & 0.470 & 0.600 & 0.601 & 0.738 & 1.000 \\
& $\beta_{\text {Sim }}$ & 0.000 & 0.222 & 0.333 & 0.371 & 0.500 & 1.000 \\
& $\beta_{\text {Nes }}$ & 0.000 & 0.095 & 0.186 & 0.230 & 0.326 & 0.771 \\
\multirow{2}{*}{ Fish } & $\beta_{\text {Sør }}$ & 0.000 & 0.875 & 1.000 & 0.881 & 1.000 & 1.000 \\
& $\beta_{\text {Sim }}$ & 0.000 & 0.778 & 1.000 & 0.824 & 1.000 & 1.000 \\
& $\beta_{\text {Nes }}$ & 0.000 & 0.000 & 0.000 & 0.056 & 0.056 & 0.444 \\
\hline
\end{tabular}

\subsection{Patterns of Dissimilarity/GDM Models of $\beta$-Diversity}

For macrophytes, geographical distance was the unique important predictor for determining the Sørensen dissimilarity component $\left(\beta_{\text {Sør }}\right)$; the model excluded all other environmental predictors (Table 4 and Figure 2). Geographical distance contributed to a lesser degree to the Simpson dissimilarity component $\left(\beta_{\text {Sim }}\right)$ while conductivity was the most important predictor in the GDM model (0.311), both explaining $22.019 \%$ of the total deviance of the fitted GDM model (Table 4). The rate and magnitude of species turnover along both gradients were exponential (Figure 2). The most important environmental gradient explaining the dissimilarity due to the nestedness component for macrophytes was altitude, which increased exponentially (coefficient: 0.170 ), with a small contribution of geographical distance (nonlinear increase, coefficient: 0.095 ), jointly explaining $8.032 \%$ of the total deviance (Table 4 and Figure 2). 
Table 4. Summary of the Generalized Dissimilarity Model (GDM), in which significant variables and their relative importance in the GDMs are presented (relative importance is determined by summing the coefficients of the I-splines from GDM). The percentage of the total deviance explained by the fitted GDM and the null deviance are also presented.

\begin{tabular}{|c|c|c|c|c|c|}
\hline Macrophytes & Null Deviance & GDM Deviance & \%Deviance Explained & Variables & Coefficients \\
\hline$\beta_{\text {Sør }}$ & 16.489 & 10.462 & 36.547 & Geographical distance & 1.103 \\
\hline \multirow[t]{2}{*}{$\beta_{\text {Sim }}$} & 24.438 & 19.057 & 22.019 & Conductivity & 0.311 \\
\hline & & & & Geographical distance & 0.559 \\
\hline \multirow{2}{*}{$\beta_{\mathrm{Nes}}$} & 21.163 & 19.462 & 8.032 & Altitude & 0.170 \\
\hline & & & & Geographical distance & 0.095 \\
\hline \multicolumn{6}{|l|}{ Fish } \\
\hline \multirow{2}{*}{$\beta_{\text {Sør }}$} & 51.272 & 45.680 & 10.910 & Altitude & 2.245 \\
\hline & & & & Geographical distance & 0.796 \\
\hline \multirow{2}{*}{$\beta_{\text {Sim }}$} & 72.574 & 65.983 & 9.082 & Altitude & 1.931 \\
\hline & & & & Geographical distance & 0.158 \\
\hline
\end{tabular}
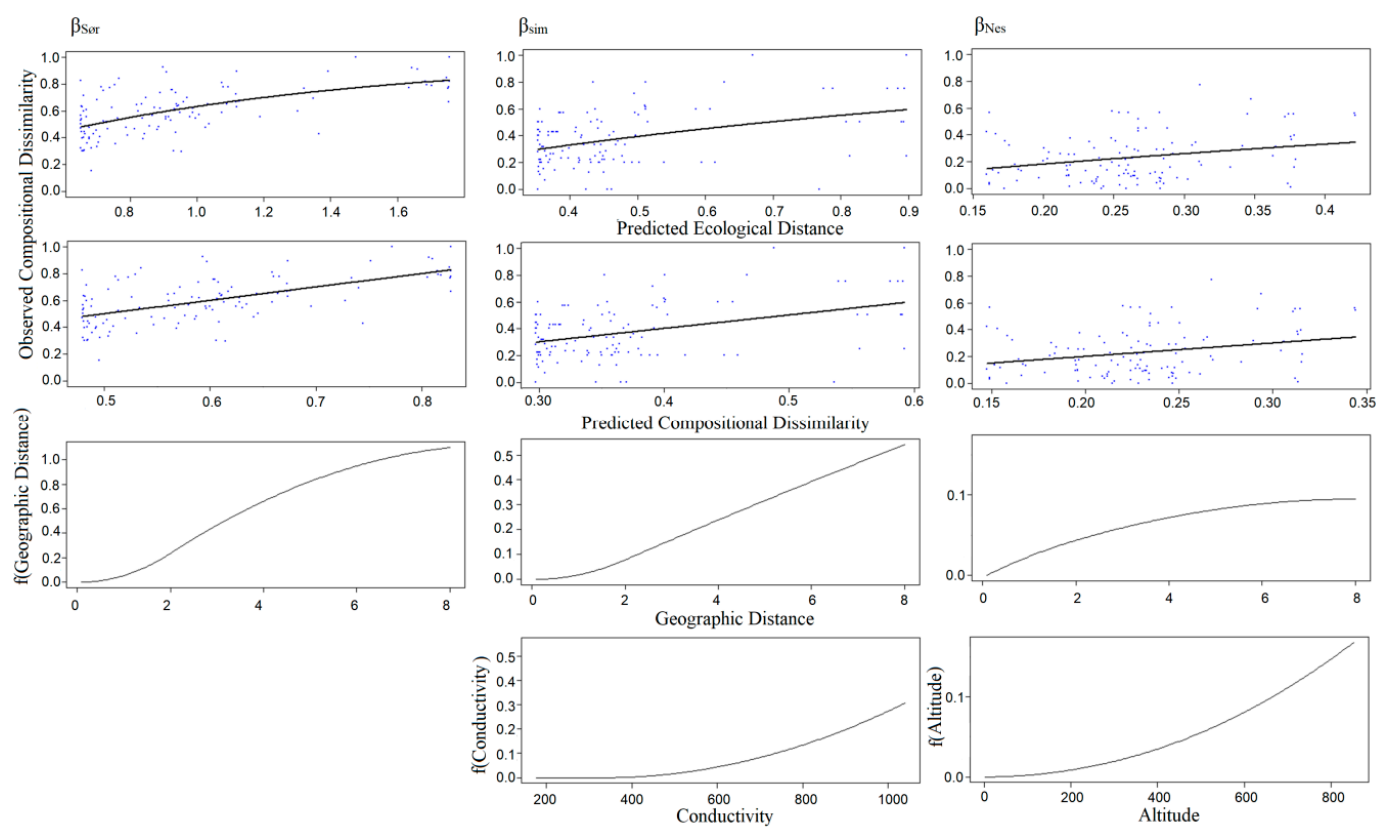

Figure 2. Relationships between the observed macrophyte Sorensen dissimilarity $\left(\beta_{\text {Sør }}\right)$, the observed macrophyte Simpson dissimilarity $\left(\beta_{\text {Sim }}\right)$, and the observed macrophyte nestedness component $\left(\beta_{\mathrm{Nes}}\right)$ with the regression equation from the Generalized Dissimilarity Model (GDM) (termed ecological distance) and the observed values versus the predicted dissimilarity. The fitted I-splines derived from the GDMs are shown for each predictor retained in the selected models, depicting the nonlinear rate of turnover across each environmental gradient (geographical distance, conductivity, and altitude). The maximum height reached by each curve indicates the total amount of compositional dissimilarity associated with that variable (it also indicates the relative importance of that variable in explaining beta diversity), holding all other variables constant. The shape of each function provides an indication of how the rate of compositional turnover varies along the gradient.

For freshwater fishes, $\beta_{\text {Sør }}$ and $\beta_{\text {Sim }}$ increased nonlinearly with geographical distance and exponentially with altitude; both predictors explained a small portion of the total variance of components ( $\beta_{\text {Sør: }} 10.910 \%$ and $\beta_{\text {Sim }}: 9.082 \%$ ) (Table 4 and Figure 3 ). However, altitude was the most important predictor of $\beta_{\text {Sør }}$ and $\beta_{\text {Sim }}$ (2.245 and 1.931, respectively). Geographical distance was identified as significant also for $\beta_{\text {Sør }}$ and $\beta_{\text {Sim }}$ of fishes, although to a lesser degree (0.796 and 0.158). The contribution of additional variables was negligible (Table 4). 

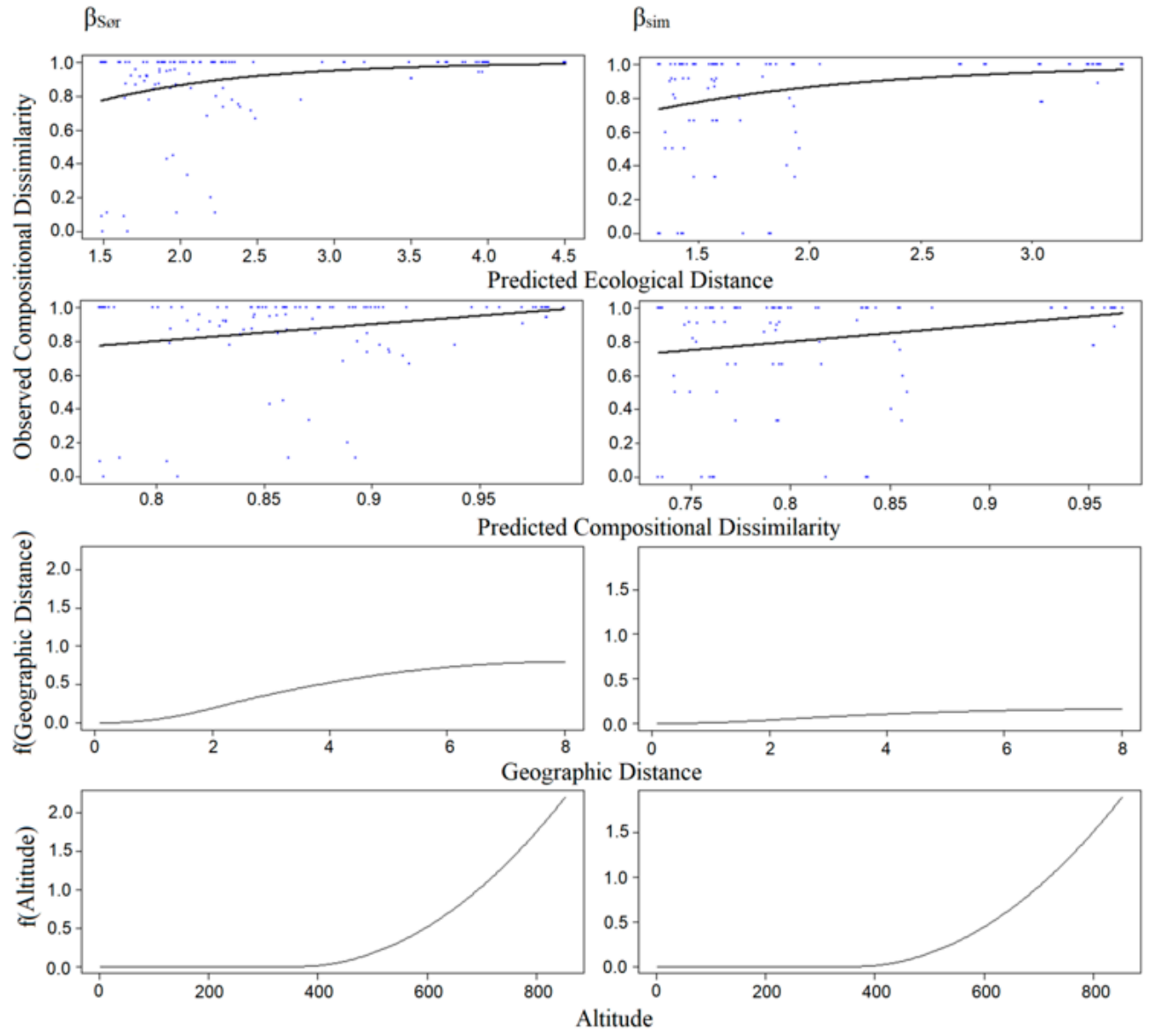

Figure 3. Relationships between the observed fish Sorensen dissimilarity $\left(\beta_{\text {Sør }}\right)$ and the observed fish Simpson dissimilarity $\left(\beta_{\text {Sim }}\right)$ with the regression equation from the Generalized Dissimilarity Model GDM (termed ecological distance) and the observed values versus the predicted dissimilarity. The fitted I-splines derived from the GDMs (partial regression fits) are shown for each predictor retained in the selected models, depicting the nonlinear rate across each environmental gradient (geographical distance and altitude). The maximum height reached by each curve indicates the total amount of compositional dissimilarity associated with that variable (it also indicates the relative importance of that variable in explaining beta diversity), holding all other variables constant. The shape of each function provides an indication of how the rate of compositional turnover varies along the gradient.

\section{Discussion}

Ecologists have long shown increased interest in disentangling $\alpha$ - and $\beta$-diversity patterns of biota, since understanding the mechanisms responsible for the complexity and maintenance of biodiversity remains at the heart of biogeography, ecology, and conservation biology. Moreover, investigations of spatial $\beta$-diversity components are considered pivotal for protecting biodiversity and can directly assist conservation planning [61]. In particular, species turnover indicates a relatively stronger species-sorting process, whereas nestedness could enhance the spatial signal [62]. If nestedness contributes more than turnover into total $\beta$ - diversity, this might suggest prioritization of a small number of ecosystems with high $\alpha$ - diversity. In contrast, if $\beta$-diversity is attributed to high turnover, conservation must target multiple sites though not necessarily the richest $[26,63,64]$.

In this study, we performed GLMs and GDMs to identify if there is congruence between $\alpha$ - and $\beta$-diversity (and its components) for two biotic groups (macrophytes and fish) in sixteen natural lakes of the unexplored biodiversity hotspot of the Southern Balkan Peninsula. Previous studies in the freshwater realm have reported contrasting results on the relationships between diversity and 
environment for different biota $[32,33]$. However, there is no previous study in the area, comparing the beta diversity patterns of multiple biota based on a common spatial scale and identical statistical analysis.

\section{1. $\alpha$-Diversity}

In agreement with our primary hypothesis, species richness was strongly associated with lake surface area in the Balkan lentic systems. As lakes are conceived as habitat islands, a positive relationship of lake area with macrophyte richness has been well established previously [65-68] and is well founded in island biogeography reflecting habitat heterogeneity. As larger lakes will likely have more microhabitats and therefore more available niches, more species are able to find a suitable habitat $[65,69]$. Fish richness per lake was also significantly correlated with lake area, a result corroborating previous findings from North America and Africa [70,71], Asia, and Europe [30,36,72,73]. The hypothesis that increased habitat heterogeneity positively affects species richness is further supported by the fact that shoreline development, which indicates a complex and expanded littoral zone that hosts diverse habitats, was identified as an important predictor of fish richness [74]. However, most of the Skadar Lake fish species, which has the largest shoreline development, move into littoral and flooded zones to spawn (nursery habitats). To sum up, lakes with more habitats support more macrophyte and fish species. Our results also highlighted $\mathrm{pH}$ as a key environmental variable for macrophyte richness. The effects of $\mathrm{pH}$ and alkalinity in shaping macrophyte richness have long been pinpointed by several studies in Europe [75,76]. In this regard, Alahuhta et al. [68] also highlighted a positive response of macrophyte richness to alkalinity in lakes of the USA, while, more recently, Elo et al. [77] demonstrated a strong positive relationship between richness and a combined factor of conductivity, $\mathrm{pH}$, and alkalinity. The $\mathrm{pH}$ level in most freshwater systems is regulated by the concentration of bicarbonate, which serves as a source of carbon for photosynthesis of submerged and floating-leaved plants that in turn influences the growth and survival of aquatic plants. Particularly, in Greece, previous works have outlined a strong association between freshwater biota diversity patterns and physical, chemical and geomorphological variables including surface area, lake depth, Secchi depth, conductivity, and temperature [30,72,78].

Macrophyte richness was positively influenced by altitude, a contrasting outcome to several previous studies [39,67,79]. For instance, Lacoul and Feedman [79] showed a clear declining trend of species richness along a wide range of altitudes (from 77 to $4750 \mathrm{~m}$ ), being attributed to adverse climate conditions in higher altitudes that restrict the distribution of certain aquatic plants. Similarly, Alahuhta [39] underpinned the importance of higher temperatures during the growing season and winter in the lowlands compared to higher altitudes, which may favor many aquatic plants, thus explaining the negative relationship between altitude and macrophyte richness. Fewer studies have shown an opposite pattern [80] suggesting that the response of macrophyte richness to altitude varies and it may depend on the altitudinal range [68,81]. Our results are in agreement with those of Chappuis et al. [80], providing evidence of a lacking effect of physical barriers (colonization restrictions) and climatic factors, such as low temperature. Moreover, it has been reported that the predominant anthropogenic pressures in lowland lakes of the Mediterranean region (hypereutrophication, weed cutting, and water level fluctuations) could be connected to species loss and lower richness [80,81], offering a possible explanation for our results. Contrary to macrophytes, fish species richness decreased with increasing altitude where low connectivity and low temperatures set an obstacle to fish colonization, suggesting a strong climatic control on Balkan freshwater fish biodiversity, as it has been extensively reported elsewhere [71,72,82]. As altitude is negatively correlated to temperature, it was not possible to clearly disentangle the relative effect of altitude and temperature in our study. It should be noted that the altitudinal gradient also reflects the biogeographical history of fish with rich ecosystems acting as refugia. 


\section{2. $\beta$-Diversity}

The study of $\beta$-diversity is crucial to pinpoint the factors driving biodiversity patterns, especially in highly heterogeneous environments, such as the Balkan Peninsula [36]. We found that different factors shaped the high compositional dissimilarity of communities in Balkan lentic habitats, although total $\beta$-diversity was lower for the macrophyte communities ( $\left.\beta_{\text {Sør }}=0.601\right)$ than for fish $\left(\beta_{\text {Sør }}=0.881\right)$. It was further shown that the compositional dissimilarity of the two biota is related to both geographical distance and different environmental gradients, demonstrating that dispersal history, ecological and biological characteristics and the different response of each biotic group to environmental gradients are responsible for the observed beta diversity patterns, which has been previously evidenced for gastropods [83].

For macrophytes, total beta diversity $\left(\beta_{\text {Sør }}\right)$ was mostly influenced by the geographical distance among lakes. Although aquatic macrophytes are known for their broad distributional ranges due to their long-distance seed dispersal strategies such as anemochory, hydrochory, and zoochory [84,85], there are studies that report that some aquatic plants may disperse more or less uniformly at distances up to $\sim 200 \mathrm{~km}$, beyond which habitat isolation usually becomes the primary limiting factor [86]. Other studies have shown that macrophyte communities are likely more influenced by spatial dispersal processes than environmental filtering in regions with a highly variable topography and dispersal barriers, such as complex mountainous environments [86]. These results are in agreement with our findings, which showed that total dissimilarity increased with geographical distance, even for distances smaller than $200 \mathrm{~km}$, reflecting the significance of the exploration of biogeographical patterns in the Balkan Peninsula. Contrary to macrophytes, we found that total fish $\beta$-diversity in Balkan lakes is mainly constrained by the altitudinal gradient, suggesting that species with narrow ranges are mainly restricted to systems located in higher altitudes. Altitude, therefore, acts as an environmental filter, selecting fish species within the corresponding thermal niche. Thus, niche processes are dominant in shaping fish communities, whereas the weak impact of geographical distance in fish compositional dissimilarity may be due to their dispersal capabilities, which are hindered by habitat fragmentation and poor habitat connectivity [87]. Nevertheless, there is evidence that dispersal may play a significant role in determining community structure of Greek freshwater assemblages, as has been shown by previous studies (e.g., [30,72]). These discrepancies in findings may be related to the differences in data time span and spatial extent of ecosystems actually used in the analyses.

Applying an additive partitioning framework, we found that species replacement (turnover) was the major component of macrophyte and fish total $\beta$-diversity in Balkan lakes, although the effect was stronger for fish ( 0.371 and 0.824 for macrophytes and fish, respectively). The complementary nestedness component accounted for $23 \%$ of total $\beta$ diversity for macrophytes whereas it was found extremely low for fish $\left(\beta_{\mathrm{Nes}}<0.1\right)$. The preponderance of the turnover component over the nestedness component has already been highlighted in previous studies $[33,88,89]$.

Macrophyte and fish beta diversity components $\left(\beta_{\mathrm{Sim}}\right.$ and $\left.\beta_{\mathrm{Nes}}\right)$ had differing responses to environmental gradients and geographical distance mainly due to differences in the mode of dispersal, e.g., good or bad dispersal ability. The compositional change (turnover component) in macrophyte assemblages is limited primarily by dispersal. Our results suggest that aquatic macrophyte turnover and nestedness are also governed by conductivity and altitude, respectively. Regarding conductivity, the results imply that water quality plays a role in defining the environmental conditions in which certain species are favored over others. Conductivity in particular has been highlighted as a key driver of macrophyte composition in the Mediterranean [80,90,91]. For instance, Fernández-Aláez et al. [81] showed that conductivity was the main predictor of macrophyte assemblages in a large number of Spanish ponds along an altitudinal gradient. Thus, high conductivity $(>800 \mu \mathrm{S} / \mathrm{cm}$ ) favored macrophyte assemblages dominated by few tolerant species such as Ceratophyllum demersum and Stuckenia pectinata, whereas waters with low ionic content could support communities with aquatic bryophytes and isoetids. Moreover, random species extinctions or colonization events across the altitudinal gradient may have led to medium levels of nestedness in macrophyte assemblages. Contrary, 
environmental filtering (the altitudinal gradient) was the main force shaping fish turnover adding evidence to the role of species sorting processes in controlling the variation in species composition [92]. In particular, lakes in high altitudes could have acted as refugia during the glacial periods or as speciation centers (Prespa Lakes' ecoregion [36]). In conclusion, endemism may have a direct effect on fish assemblages by promoting speciation (see also [93] for consistency). These results are, therefore, in line with a growing body of evidence, suggesting a positive relationship between species composition and environmental heterogeneity in fish communities [32], although other studies [30,72] have shown that dispersal limitation played a more significant role in shaping Greek freshwater fish communities than environmental heterogeneity. Last, the nestedness component of beta diversity was negligible for fish $\left(\beta_{\mathrm{Nes}}<0.1\right)$, as has been reported elsewhere [36].

\subsection{Conservation Implications}

The current study showed that $\alpha$-diversity patterns across the two biological groups of macrophytes and fish are not uniform and were shaped by different drivers under the same spatial scale, suggesting differences in their evolutionary histories. We also found weak congruence in the main factors driving $\beta$ - diversity of the two biological groups, probably due to the different dispersal modes. Our findings support previous studies indicating that species richness and compositional dissimilarity among freshwater biota are shaped by different/contrasting factors [94] and, thus, conservation plans and bioassessments of human disturbance need to include multiple biota. Our results further suggest that the partitioning of $\beta$-diversity components should be considered in the future for optimizing conservation strategies. We showed that species turnover was the major driver of $\beta$-diversity and, thus, conservation efforts must aim to increase the network of protected freshwater areas across the Balkan Peninsula to maximize the protection of species diversity [95]. Ultimately, this study may serve as a benchmark for future studies towards ensuring the sustainable management of the Balkan freshwater biodiversity. In this context, our findings have potentially important implications for the European research agenda regarding freshwater ecosystems.

Supplementary Materials: The following are available online at http://www.mdpi.com/2073-4441/12/7/1984/s1, Table S1: Environmental data of lakes extracted from the literature and considered in the analyses. Figure S1: Partial dependence plots showing the responses of fish (left) and macrophyte richness (right) to each predictor.

Author Contributions: Conceptualization, A.O. and K.S.; methodology, A.O.; software, K.S.; formal analysis, A.O.; investigation, A.O.; resources, A.O. and K.S.; data curation, A.O. and K.S.; and writing-original draft preparation, A.O. and K.S. All authors have read and agreed to the published version of the manuscript.

Funding: This research received no external funding.

Acknowledgments: The authors would like to thank the academic editor and two anonymous reviewers for the insightful and fruitful comments that improved the manuscript.

Conflicts of Interest: The authors declare no conflict of interest.

\section{References}

1. Darwin, C. The Voyage of the Beagle. Natural History Library; Anchor Press: Norwell, MA, USA, 1839.

2. Wallace, A.R. Tropical Nature, and Other Essays; Macmillan \& Co.: London, UK; New York, NY, USA, 1878; p. 356.

3. MacArthur, R.H. Geographical Ecology: Patterns in the Distribution of Species; Harper and Row: New York, NY, USA, 1972.

4. Ricklefs, R.E.; Jenkins, D.G. Biogeography and ecology: Towards the integration of two disciplines. Philos. Trans. R. Soc. B Biol. Sci. 2011, 366, 2438-2448. [CrossRef] [PubMed]

5. Anderson, M.J.; Crist, T.O.; Chase, J.M.; Vellend, M.; Inouye, B.D.; Freestone, A.L.; Sanders, N.J.; Cornell, H.V.; Comita, L.S.; Davies, K.F.; et al. Navigating the multiple meanings of b diversity: A roadmap for the practicing ecologist. Ecol. Lett. 2010, 14, 19-28. [CrossRef] [PubMed]

6. Heino, J.; Alahuhta, J.; Fattorini, S. Phylogenetic diversity of regional beetle faunas at high latitudes: Patterns, drivers and chance along ecological gradients. Biodivers. Conserv. 2015, 24, 2751-2767. [CrossRef] 
7. Veech, J.A.; Summerville, K.S.; Crist, T.O.; Gering, J.C. The additive partitioning of species diversity: Recent revival of an old idea. Oikos 2002, 99, 3-9. [CrossRef]

8. Ligeiro, R.; Melo, A.S.; Callisto, M. Spatial scale and the diversity of macroinvertebrates in a Neotropical catchment. Freshw. Biol. 2010, 55, 424-435. [CrossRef]

9. Francisco-Ramos, V.; Arias-González, J.E. Additive Partitioning of Coral Reef Fish Diversity across Hierarchical Spatial Scales throughout the Caribbean. PLoS ONE 2013, 8, e78761. [CrossRef]

10. Matsuda, J.T.; Martens, K.; Higuti, J. Diversity of ostracod communities (Crustacea, Ostracoda) across hierarchical spatial levels in a tropical floodplain. Hydrobiologia 2015, 762, 113-126. [CrossRef]

11. Mittelbach, G.G. Community Ecology; Sinauer Associates: Sunderland, MS, USA, 2012.

12. Simberloff, D.; Connor, E.F. Missing Species Combinations. Am. Nat. 1981, 118, 215-239. [CrossRef]

13. Ricklefs, R.E. Community Diversity: Relative Roles of Local and Regional Processes. Science 1987, 235, 167-171. [CrossRef]

14. Tuomisto, H.; Ruokolainen, K.; Aguilar, M.; Sarmiento, A. Floristic patterns along a 43-km long transect in an Amazonian rain forest. J. Ecol. 2003, 91, 743-756. [CrossRef]

15. Leibold, M.A.; Holyoak, M.; Mouquet, N.; Amarasekare, P.; Chase, J.M.; Hoopes, M.F.; Holt, R.D.; Shurin, J.B.; Law, R.; Tilman, D.; et al. The metacommunity concept: A framework for multi-scale community ecology. Ecol. Lett. 2004, 7, 601-613. [CrossRef]

16. Gilbert, B.; Lechowicz, M.J. Neutrality, niches, and dispersal in a temperate forest understory. Proc. Natl. Acad. Sci. USA 2004, 101, 7651-7656. [CrossRef] [PubMed]

17. Cottenie, K. Integrating environmental and spatial processes in ecological community dynamics. Ecol. Lett. 2005, 8, 1175-1182. [CrossRef] [PubMed]

18. Melo, A.S.; Rangel, T.F.; Diniz-Filho, J.A.F. Environmental drivers of beta-diversity patterns in New-World birds and mammals. Ecography 2009, 32, 226-236. [CrossRef]

19. Nekola, J.C.; White, P. The distance decay of similarity in biogeography and ecology. J. Biogeogr. 1999, 26, 867-878. [CrossRef]

20. Hubbell, S.P. The Unified Neutral Theory of Biodiversity and Biogeography; Princeton University Press: Princeton, NJ, USA, 2001.

21. Baselga, A. The relationship between species replacement, dissimilarity derived from nestedness, and nestedness. Glob. Ecol. Biogeogr. 2012, 21, 1223-1232. [CrossRef]

22. Qian, H.; Ricklefs, R.E.; White, P.S. Beta diversity of angiosperms in temperate floras of eastern Asia and eastern North America. Ecol. Lett. 2005, 8, 15-22. [CrossRef]

23. Kraft, N.; Comita, L.; Chase, J.M.; Sanders, N.J.; Swenson, N.G.; Crist, T.O.; Stegen, J.C.; Vellend, M.; Boyle, B.L.; Anderson, M.J.; et al. Disentangling the drivers of $\beta$ diversity along latitudinal and elevational gradients. Science 2011, 333, 1755-1758. [CrossRef]

24. Wen, Z.; Yang, Q.; Quan, Q.; Xia, L.; Ge, D.; Lv, X. Multiscale partitioning of small mammal?-diversity provides novel insights into the Quaternary faunal history of Qinghai-Tibetan Plateau and Hengduan Mountains. J. Biogeogr. 2016, 43, 1412-1424. [CrossRef]

25. Wright, D.H.; Reeves, J.H. On the meaning and measurement of nestedness of species assemblages. Oecologia 1992, 92, 416-428. [CrossRef]

26. Baselga, A. Partitioning the turnover and nestedness components of beta diversity. Glob. Ecol. Biogeogr. 2009, 19, 134-143. [CrossRef]

27. Heino, J. A macroecological perspective of diversity patterns in the freshwater realm. Freshw. Biol. 2011, 56, 1703-1722. [CrossRef]

28. Beisner, B.; Neto, P.P.; Lindström, E.S.; Barnett, A.; Longhi, M.L. The role of environmental and spatial processes in structuring lake communities from bacteria to fish. Ecology 2006, 87, 2985-2991. [CrossRef]

29. Soininen, J.; Mc Donald, R.; Hillebrand, H. The distance decay of similarity in ecological communities. Ecography 2007, 30, 3-12. [CrossRef]

30. Mazaris, A.D.; Moustaka-Gouni, M.; Michaloudi, E.; Bobori, D.C. Biogeographical patterns of freshwater micro- and macroorganisms: A comparison between phytoplankton, zooplankton and fish in the eastern Mediterranean. J. Biogeogr. 2010, 37, 1341-1351. [CrossRef]

31. Heino, J.; Soininen, J.; Alahuhta, J.; Lappalainen, J.; Virtanen, R. Metacommunity ecology meets biogeography: Effects of geographical region, spatial dynamics and environmental filtering on community structure in aquatic organisms. Oecologia 2017, 183, 121-137. [CrossRef] 
32. Ceschin, F.; Bini, L.M.; Padial, A.A. Correlates of fish and aquatic macrophyte beta diversity in the Upper Paraná River floodplain. Hydrobiologia 2018, 805, 377-389. [CrossRef]

33. Lansac-Tôha, F.M.; Heino, J.; Quirino, B.A.; Moresco, G.A.; Peláez, O.; Meira, B.R.; Rodrigues, L.C.; Jati, S.; Lansac-Tôha, F.A.; Velho, L.F.M.; et al. Differently dispersing organism groups show contrasting beta diversity patterns in a dammed subtropical river basin. Sci. Total. Environ. 2019, 691, 1271-1281. [CrossRef]

34. Stendera, S.; Adrian, R.; Bonada, N.; Cañedo-Argüelles, M.; Hugueny, B.; Januschke, K.; Pletterbauer, F.; Hering, D. Drivers and stressors of freshwater biodiversity patterns across different ecosystems and scales: A review. Hydrobiologia 2012, 696, 1-28. [CrossRef]

35. Kryštufek, B.; Reed, J.M. Pattern and Process in Balkan Biodiversity-An overview. In Balkan Biodiversity, Pattern and Process in the European Hotspot; Griffiths, H.J., Kryštufek, B., Reed, J.M., Eds.; Kluwer Academic Publishers: Dordrecht, The Netherlands, 2004; pp. 1-8.

36. Koutsikos, N.; Leprieur, F.; Leonardos, I.D. Biogeography of freshwater fishes of the Balkan Peninsula. Hydrobiologia 2014, 738, 205-220. [CrossRef]

37. Bănărescu, P.M. Distribution Pattern of the Aquatic Fauna of the Balkan Peninsula. In Balkan Biodiversity, Pattern and Process in the European Hotspot; Griffiths, H.J., Kryštufek, B., Reed, J.M., Eds.; Kluwer Academic Publishers: Dordrecht, The Netherlands, 2004; pp. 203-217.

38. Radoman, P. Hydrobioidea, a Superfamily of Prosobranchia (Gastropoda) II: Origin, Zoogeography, Evolution in the Balkans and Asia Minor. Monographs of the Institute of Zoology; Department of Biology, Faculty of Science, Belgrade: Belgrade, Serbia, 1985.

39. Alahuhta, J. Geographic patterns of lake macrophyte communities and species richness at regional scale. J. Veg. Sci. 2015, 26, 564-575. [CrossRef]

40. Hollister, J.W. Lakemorpho: Lake Morphometry Metrics. R package Version 1.1.1. 2018. Available online: https://CRAN.R-project.org/package=lakemorpho (accessed on 1 May 2018).

41. GMAO. MERRA-2 tavg1_2d_slv_Nx: 2d,1-Hourly,Time-Averaged,Single-Level,Assimilation,Single-Level Diagnostics V5.12.4, Greenbelt, MD, USA, Goddard Earth Sciences Data and Information Services Center (GES DISC). Available online: http://www.soda-pro,com/el/web-services/meteo-data/ (accessed on 1 May 2018). [CrossRef]

42. Koumpli-Sovantzi, L. The aquatic flora of Aetoloakarnania (W Greece). Willdenowia 1989, 18, 377-385.

43. Papastergiadou, E.; Babalonas, D. Aquatic flora of N. Greece I. Hydrophytes. Wildenowia 1993, 23, $137-142$.

44. Sarika-Hatzinikolaou, M.; Yannitsaros, A.; Babalonas, D. The macrophytic vegetation of seven aquatic ecosystems of Epirus (NW Greece). Phytocoenologia 2003, 33, 93-151. [CrossRef]

45. Valchev, V.; Georgiev, V.; Ivanova, D.; Tsoneva, S.; Janauer, G. Conservationally Important Macrophytes in the Bulgarian Stretch of the danube River and the Near Water Bodies. In Proceedings of the 36th international conference of IAD, Austrian Committee Danube Research, Ed, Vienna, Austria, 4-8 September 2006; pp. 122-126.

46. Stefanidis, K.; Papastergiadou, E. Aquatic vegetation and related abiotic environment in a shallow urban lake of Greece. Belg. J. Bot. 2007, 140, 25-38.

47. Talevska, M.; Petrovic, D.; Milosevic, D.; Talevski, T.; Maric, D.; Talevska, A. Biodiversity of macrophyte vegetation from Lake Prespa, Lake Ohrid and Lake Skadar. Biotechnol. Biotechnol. Equip. 2009, 23, 931-935. [CrossRef]

48. Manolaki, P.; Tsakiri, E.; Papastergiadou, E. Inventory of aquatic and riparian flora of Acheron and Louros rivers, and Zirou Lake in western Greece. Fresenius Environ. Bull. 2011, 20, 861-874.

49. Stefanidis, K. Ecological Assessment of Lakes of NW Greece with Emphasis on the Associations between Aquatic Macrophytes, Zooplankton and Water Quality. Ph.D. Thesis, Department of Biology, University of Patras, Patras, Greece, 2012. [CrossRef]

50. Leprieur, F.; Oikonomou, A. The need for richness-independent measures of turnover when delineating biogeographical regions. J. Biogeogr. 2014, 41, 417-420. [CrossRef]

51. Baselga, A.; Orme, D.; Villeger, S.; Bortoli, D.; Leprieur, F. Betapart: Partitioning Beta Diversity Into Turnover and Nestedness Components. R Package Version 1.3. Available online: https://cran.r-project.org/web/ packages/betapart/index.html (accessed on 13 July 2020).

52. Wei, T.; Simko, V.; Levy, M.; Xie, Y.; Jin, Y.; Zemla, J. Corrplot: Visualization of a Correlation Matrix. R Package Version 0.84. 2017. Available online: https://cran.r-project.org/web/packages/corrplot/index.html (accessed on 13 July 2020). 
53. Fox, J.; Weisberg, S.; Price, B.; Adler, D.; Bates, D.; Baud-Bovy, G.; Bolker, B.; Ellison, S.; Firth, D.; Friendly, M.; et al. R-Core. Car: Companion to Applied Regression. R Package Version 3.0-6. 2019. Available online: https://cran.r-project.org/web/packages/car/index.html (accessed on 13 July 2020).

54. Quinn, G.P.; Keough, M.G. Experimental Design and Data Analysis for Biologists; Cambridge University Press: New York, NY, USA, 2002.

55. Barton, K. MuMIn: Multi-Model Inference. R Package Version 1.42.1. 2018. Available online: https://CRAN.Rproject.org/package=MuMIn (accessed on 13 July 2020).

56. Burnham, K.P.; Anderson, D.R. Model Selection and Multimodel Inference: A Practical Information-Theoretic Approach; Springer: New York, NY, USA, 2002.

57. Venables, W.N.; Ripley, B.D. Modern Applied Statistics with S, 4th ed.; Springer: New York, NY, USA, 2002.

58. Mazerolle, M.J. AICcmodavg: Model Selection and Multimodel Inference Based on (Q) AIC(c). R Package Version 1.27. 2013. Available online: https://cran.r-project.org/web/packages/AICcmodavg/index.html (accessed on 13 July 2020).

59. Ferrier, S.; Guisan, A. Spatial modelling of biodiversity at the community level. J. Appl. Ecol. 2006, 43, 393-404. [CrossRef]

60. Ferrier, S.; Manion, G.; Elith, J.; Richardson, K. Using generalized dissimilarity modelling to analyse and predict patterns of beta diversity in regional biodiversity assessment. Divers. Distrib. 2007, 13, 252-264. [CrossRef]

61. Socolar, J.B.; Gilroy, J.J.; Kunin, W.E.; Edwards, D.P. How should beta-diversity inform biodiversity conservation? Trends Ecol. Evol. 2016, 31, 67-80. [CrossRef] [PubMed]

62. Yang, Y.; Hu, R.; Lin, Q.; Hou, J.; Liu, Y.; Han, B.-P.; Naselli-Flores, L. Spatial structure and $\beta$-diversity of phytoplankton in Tibetan Plateau lakes: Nestedness or replacement? Hydrobiologia 2017, 808, 301-314. [CrossRef]

63. Guareschi, S.; Abellan, P.; Laini, A.; Green, A.J.; Sanchez-Zapata, J.A.; Velasco, J.; Millan, A. Cross-taxon congruence in wetlands: Assessing the value of waterbirds as surrogates of macroinvertebrate biodiversity in Mediterranean Ramsar sites. Ecol. Indic. 2015, 49, 204-215. [CrossRef]

64. Loiseau, N.; Legras, G.; Kulbicki, M.; Mérigot, B.; Harmelin-Vivien, M.; Mazouni, N.; Galzin, R.; Gaertner, J. Multi-component $\beta$-diversity approach reveals conservation dilemma between species and functions of coral reef fishes. J. Biogeogr. 2016, 44, 537-547. [CrossRef]

65. Rørslett, B. Principal determinants of aquatic macrophyte richness in northern European lakes. Aquat. Bot. 1991, 39, 173-193. [CrossRef]

66. Dodson, S.I.; Arnott, S.E.; Cottingham, C.L. The relationship in lake communities between primary productivity and species richness. Ecology 2000, 81, 2662-2679. [CrossRef]

67. Jones, J.I.; Li, W.; Maberly, S.C. Area, altitude and aquatic plant diversity. Ecography 2003, 26, 411-420. [CrossRef]

68. Alahuhta, J.; Kosten, S.; Akasaka, M.; Auderset, D.; Azzella, M.M.; Bolpagni, R.; Bove, C.P.; Chambers, P.A.; Chappuis, E.; Clayton, J.; et al. Global variation in the beta diversity of lake macrophytes is driven by environmental heterogeneity rather than latitude. J. Biogeogr. 2017, 44, 1758-1769. [CrossRef]

69. Toivonen, H.; Huttunen, P. Aquatic macrophytes and ecological gradients in 57 small lakes in southern Finland. Aquat. Bot. 1995, 51, 197-221. [CrossRef]

70. Barbour, C.D.; Brown, J.H. Fish species diversity in lakes. Am. Nat. 1974, 108, 473-489. [CrossRef]

71. Amarasinghe, U.S.; Welcomme, R.L. An Analysis of Fish Species Richness in Natural Lakes. Environ. Biol. Fishes 2002, 65, 327-339. [CrossRef]

72. Drakou, E.; Bobori, D.C.; Kallimanis, A.S.; Mazaris, A.D.; Sgardelis, S.P.; Pantis, J.D. Freshwater fish community structured more by dispersal limitation than by environmental heterogeneity. Ecol. Freshw. Fish 2009, 18, 369-379. [CrossRef]

73. Brucet, S.; Pédron, S.; Mehner, T.; Lauridsen, T.L.; Argillier, C.; Winfield, I.J.; Volta, P.; Emmrich, M.; Hesthagen, T.; Holmgren, K.; et al. Fish diversity in European lakes: Geographical factors dominate over anthropogenic pressures. Freshw. Biol. 2013, 58, 1779-1793. [CrossRef]

74. Eadie, J.M.; Keast, A. Resource heterogeneity and fish species diversity in lakes. Can. J. Zool. 1984, 62, 1689-1695. [CrossRef]

75. Vestergaard, O.; Sand-Jensen, K. Aquatic macrophyte richness in Danish lakes in relation to alkalinity, transparency, and lake area. Can. J. Fish. Aquat. Sci. 2000, 57, 2022-2031. [CrossRef] 
76. Lauridsen, T.; Jeppesen, E.; Declerck, S.A.J.; De Meester, L.; Conde-Porcuna, J.M.; Rommens, W.; Brucet, S. The importance of environmental variables for submerged macrophyte community assemblage and coverage in shallow lakes: Differences between northern and southern Europe. Hydrobiologia 2014, 744, 49-61. [CrossRef]

77. Elo, M.; Alahuhta, J.; Kanninen, A.; Meissner, K.K.; Seppälä, K.; Mönkkönen, M. Environmental Characteristics and Anthropogenic Impact Jointly Modify Aquatic Macrophyte Species Diversity. Front. Plant Sci. 2018, 9, 1001. [CrossRef]

78. Stefanidis, K.; Papastergiadou, E. Relationships between lake morphometry, water quality and aquatic macrophytes in Greek lakes. Fresen. Environ. Bull. 2012, 21, 3018-3026.

79. Lacoul, P.; Freedman, B. Relationships between aquatic plants and environmental factors along a steep Himalayan altitudinal gradient. Aquat. Bot. 2006, 84, 3-16. [CrossRef]

80. Chappuis, E.; Gacia, E.; Ballesteros, E. Environmental factors explaining the distribution and diversity of vascular aquatic macrophytes in a highly heterogeneous Mediterranean region. Aquat. Bot. 2014, 113, 72-82. [CrossRef]

81. Fernández-Aláez, C.; Fernández-Aláez, M.; García-Criado, F.; García-Girón, J. Environmental drivers of aquatic macrophyte assemblages in ponds along an altitudinal gradient. Hydrobiologia 2016, 812, 79-98. [CrossRef]

82. Hrivnák, R.; Ot'Ahel'Ová, H.; Kochjarová, J.; Pal'Ove-Balang, P. Effect of environmental conditions on species composition of macrophytes-Study from two distinct biogeographical regions of Central Europe. Knowl. Manag. Aquat. Ecosyst. 2013, 411, 09. [CrossRef]

83. Georgopoulou, E.; Neubauer, T.A.; Harzhauser, M.; Kroh, A.; Mandic, O. Distribution patterns of European lacustrine gastropods-A result of environmental factors and deglaciation history. Hydrobiologia 2016, 775, 69-82. [CrossRef]

84. Lukács, B.A.; Vojtkó, A.E.; Mesterházy, A.; Molnar V., A. Süveges, K.; Végvári, Z.; Brusa, G.; Cerabolini, B.E.L. Growth-form and spatiality driving the functional difference of native and alien aquatic plants in Europe. Ecol. Evol. 2017, 7, 950-963. [CrossRef] [PubMed]

85. Chambers, P.A.; Lacoul, P.; Murphy, K.J.; Thomaz, S.M. Global diversity of aquatic macrophytes in freshwater. Hydrobiologia 2008, 595, 9-26. [CrossRef]

86. Alahuhta, J.; Lindholm, M.; Bove, C.; Chappuis, E.; Clayton, J.; De Winton, M.; Feldmann, T.; Ecke, F.; Gacia, E.; Grillas, P.; et al. Global patterns in the metacommunity structuring of lake macrophytes: Regional variations and driving factors. Oecologia 2018, 188, 1167-1182. [CrossRef]

87. Radinger, J.; Wolter, C. Patterns and predictors of fish dispersal in rivers. Fish Fish. 2013, 15, 456-473. [CrossRef]

88. Alahuhta, J.; Johnson, L.B.; Olker, J.; Heino, J. Species sorting determines variation in the community composition of common and rare macrophytes at various spatial extents. Ecol. Complex. 2014, 20, 61-68. [CrossRef]

89. Heino, J.; Melo, A.S.; Jyrkänkallio-Mikkola, J.; Petsch, D.K.; Saito, V.S.; Tolonen, K.T.; Bini, L.M.; Landeiro, V.L.; Silva, T.S.F.; Pajunen, V.; et al. Subtropical streams harbour higher genus richness and lower abundance of insects compared to boreal streams, but scale matters. J. Biogeogr. 2018, 45, 1983-1993. [CrossRef]

90. Sleith, R.S.; Wehr, J.D.; Karol, K.G. Untangling climate and water chemistry to predict changes in freshwater macrophyte distributions. Ecol. Evol. 2018, 8, 2802-2811. [CrossRef] [PubMed]

91. Stefanidis, K.; Sarika, M.; Papastegiadou, E. Exploring environmental predictors of aquatic macrophytes in water-dependent Natura 2000 sites of high conservation value: Results from a long-term study of macrophytes in Greek lakes. Aquat. Conserv. Mar. Freshw. Ecosyst. 2019, 29, 1133-1148. [CrossRef]

92. Wojciechowski, J.; Heino, J.; Bini, L.M.; Padial, A.A. The strength of species sorting of phytoplankton communities is temporally variable in subtropical reservoirs. Hydrobiologia 2017, 800, 31-43. [CrossRef]

93. Boll, T.; Levi, E.E.; Bezirci, G.; Özuluğ, M.; Tavşanoğlu, Ü.N.; Özcan, S.; Brucet, S.; Jeppesen, E.; Beklioğlu, M.; Çakıroğlu, A.I. Fish assemblage and diversity in lakes of western and central Turkey: Role of geo-climatic and other environmental variables. Hydrobiologia 2016, 771, 31-44. [CrossRef] 
94. Heino, J. Are indicator groups and cross-taxon congruence useful for predicting biodiversity in aquatic ecosystems? Ecol. Indic. 2010, 10, 112-117. [CrossRef]

95. Qin, J.; Liu, X.; Xu, Y.; Wu, X.; Ouyang, S. Beta diversity patterns of fish and conservation implications in the Luoxiao Mountains, China. ZooKeys 2019, 817, 73-93. [CrossRef]

(C) 2020 by the authors. Licensee MDPI, Basel, Switzerland. This article is an open access article distributed under the terms and conditions of the Creative Commons Attribution (CC BY) license (http://creativecommons.org/licenses/by/4.0/). 